\title{
Down-regulation of Egr-1 by siRNA inhibits growth of human prostate carcinoma cell line PC-3
}

\author{
EDUARDO PARRA $^{1}$, ARNALDO ORTEGA $^{1}$ and LEONARDO SAENZ ${ }^{2}$ \\ ${ }^{1}$ Biomedical Experimental Laboratory, Department of Biology, Faculty of Sciences, Tarapaca University of Arica, \\ Avenida General Velásquez 1775, Arica; ${ }^{2}$ Faculty of Veterinary Medicine, University of Chile, \\ Campus Antumapu, Avenida Santa Rosa 11.735 (Paradero 34) La Pintana, Santiago, Chile
}

Received June 19, 2009; Accepted August 14, 2009

DOI: $10.3892 /$ or_00000595

\begin{abstract}
The inhibitory effect of a specific small EGR-1 interfering RNA ( $\mathrm{siRNA}$ ) on cell proliferation and the expression of EGR-1 in human prostate carcinoma cell lines PC-3 and LNCaP was investigated. To knockdown Egr-1 expression, a siRNA targeting against Egr-1 was synthesized and transfected into PC-3 and LNCaP cells. The downregulation of Egr-1 expression at both mRNA and protein levels were detected by reverse transcription-polymerase chain reaction (RT-PCR) and Western blot analysis. The transcription activity was determined by luciferase expression. Cell proliferation inhibition rates were determined by soft agar and methyl thiazolyl tetrazolium (MTT) assay. The effect of Egr-1 siRNA on cell cycle distribution and cell apoptosis was determined by flow cytometry (FCM). RNA interference efficiently suppressed the Egr-1 expression in PC-3 and LNCaP cells. At $96 \mathrm{~h}$ after transfection, the expression inhibition rate was $44.52 \%$ at mRNA level detected by RT-PCR and $40.17 \%$ at protein level by Western blot analysis. The cell proliferation inhibition rates at 24, 48, 96 and $120 \mathrm{~h}$ after Egr-1 siRNA and non-silencing siRNA transfection, were 5, 25.06, 65.61 and $78.36 \%$, respectively for PC-3 cells and 23, 40.3, 75.9 and $67.4 \%$, respectively for LNCaP cells. The apoptosis rate was similar for both PC-3 and $\mathrm{LNCaP}$ and the number of cells was increased in $\mathrm{G}_{0} / \mathrm{G}_{1}$ phase from 38.2 to $88.6 \%$, and decreased in $S$ and $G_{2} / M$ phase at $96 \mathrm{~h}$ after transfection. Down-regulation of Egr-1 results in significant inhibition of tumor growth in vitro. The inhibition of Egr-1 expression can induce apoptosis of PC-3 cells. The use of Egr-1 siRNA deserves further investigation as a novel approach to cancer therapy.
\end{abstract}

Correspondence to: Dr Eduardo Parra, Department of Biology, Biomedical Experimental Laboratory, Sciences Faculty, University of Tarapaca, Avenida General Velásquez 1775, Arica, Chile E-mail: eparra@uta.cl

Key words: prostate carcinoma, early growth response gene, short RNA interference, apoptosis

\section{Introduction}

The transcription factor, Egr-1, is rapidly induced by growth factors to transduce the proliferative signal. The induction of Egr-1 by external stimuli is generally transient but appears to be sustained in some prostate tumor cell lines and tumors, suggesting that Egr-1 stimulates tumor cell growth and this could have an important function because its expression level increases with the degree of malignancy as measured by the Gleason grade of the tumor (1). This seems to be specific to prostate tumor cells, because in mammary and lung tumors, as well as most normal tissues, Egr-1 expression is low (2-6). In addition Egr-1 overexpression is correlated with the loss of its co-repressor NAB2 in primary prostate carcinoma $(7,8)$. This disruption of the balance between Egr-1 and NAB2 expression results in a high Egr-1 transcriptional activity in prostate carcinoma cells (1). On the contrary, in breast, lung and brain tumors, Egr-1 expression is often absent or reduced and when re-expressed, results in growth suppression $(2,3,9,10)$. Another contradiction is that after stress stimuli to some cell types, Egr-1 is required for programmed cell death or apoptosis in both normal and tumor cells. Egr-1 also plays a role in tumor progression, through the hypoxic signal is generated in growing tumors. Egr-1 is highly induced under these conditions and its activities stimulate angiogenesis and improved survival of tumor cells $(6,11,12)$.

RNA interference (RNAi) was originally identified as an endogenous mechanism for post-transcriptional gene silencing in plants and nematodes and is now an established technique for experimental 'knockdown' of gene expression to establish function in mammalian cells $(13,14)$. RNAi has typically been achieved in cultured mammalian cells by transfection of chemically synthesized gene-specific $21 \mathrm{nt}$ small interfering RNAs (siRNAs). Introduction of these molecules leads to reduced expression of specific mRNAs, thus permitting the analysis of a knockdown phenotype without the need for time-consuming gene-targeting studies. Recent reports have shown that siRNAs can also be used to analyze gene function in primary immune cells, including $\mathrm{T}$ cells $(15-17)$ and dendritic cells (DCs) (1). The effect of siRNA involves posttranscriptional gene silencing via a process in which doublestranded RNA (dsRNA) inhibits gene expression in a sequence-dependent manner through degradation of the corresponding mRNA. Its blocking action on gene expression 
has been successfully observed in rat and human cells cultured in vitro, and the knock-down of genes in cells has been achieved $(18,19)$. In addition, the development of retroviral constructs in which the polymerase-III H1-RNA gene promoter synthesizes siRNA-like transcripts, allows stable expression of siRNA, thus rendering this technology applicable as gene transfer $(20,21)$.

Thus, the ability to stably express siRNA from a retroviral vector allowed Egr-1 mRNA and EGR-1 protein to be knocked down inducing apoptosis and loss of the adherence capacicity of the cells in soft agar both in PC-3 and LNCaP-cells. However, one of the major concerns about Egr-1 overexpression in carcinoma tumors is that it would become associated with a loss in functionality of the prostate cells and/or the development of autonomous growth. Therefore, it can be used as a powerful approach to silence mammalian gene expression for gene function studies (22-24).

In the present study, siRNA targeting to the Egr-1 gene was introduced into prostate carcinoma cell lines PC-3 and LNCaP, which overexpresses EGR-1. These observations strongly suggest that Egr-1 is involved in prostate cancer progression despite its known role as a tumor-suppressor in several other types of human cancers (6-8).

\section{Materials and methods}

Cell lines and culture. Human prostate carcinoma cell lines PC-3 and LNCaP were a present from Dr Dan Mercola (The SKCC, La Jolla, CA, USA). The cells were cultured in RPMI-1640 medium supplemented with $100 \mathrm{ml} / \mathrm{l}$ fetal bovine serum (FBS), $8 \times 10^{5} \mathrm{U} / 1$ penicillin and $0.1 \mathrm{~g} / 1$ streptomycin in humidified incubator containing $50 \mathrm{ml} / 1 \mathrm{CO}_{2}$ at $37^{\circ} \mathrm{C} \mathrm{(25)}$.

siRNA preparation and transfection of short interfering RNA. siRNA oligonucleotides with two thymidine residues ( $\mathrm{tt}$ ) at the 3'-end of the sequence were designed for Egr-1 (sense, 5'-CAGCAGCAGCAGCAGCAGCtt-3'-hairping-TTC AAGAGA- antisense, 5'-GCTGCTGCTGCTGCTGttttta-3'). Cells were treated in parallel with a non-silencing siRNA (sense, 5'-UUCUCCGAACGUGUCACGUtt-3'; antisense, 5'-ACGUGACACGUUCGGAGAAtt-3') as control oligonucleotides were synthesized by Shanghai Genechem Co. These cells were cultured in medium without antibiotics, and $24 \mathrm{~h}$ before transfection resulting in a confluence of the cell monolayer by $50-70 \%$. Specific pTER-Egr-1 siRNA or nonsilencing siRNA (70 nmol) were mixed with Lipofectamine ${ }^{\mathrm{TM}}$ 2000 (Invitrogen) according to manufacturer's recommendation and added to the cells. After $6 \mathrm{~h}$ at $37^{\circ} \mathrm{C}$, the medium was changed, and the cells were cultivated in RPMI-1640 supplemented with $10 \%$ heat-inactivated FBS.

3-(4,5-methylthiazol-2-yl)-2,5-diphenyl-tetrazolium bromide (MTT) assay. PC-3 and LNCaP cells $\left(5 \times 10^{5}\right)$ were placed onto 96-well plates in RPMI-1640 containing 10\% FBS in a final volume of $0.1 \mathrm{ml}$. The next day, the cells were treated with the pTER siRNA. MTT was added $(20 \mathrm{ml} /$ well of $5 \mathrm{~g} / \mathrm{l}$ solution in PBS) after culture for 24,48 and $72 \mathrm{~h}$. When incubated at $37^{\circ} \mathrm{C}$ for $4 \mathrm{~h}$, the reaction was stopped by addition of $100 \mathrm{ml}$ DMSO. The reaction product was quantified by measuring the absorbance at $490 \mathrm{~nm}$ using an ELISA reader (Wallac 1420 Victor 2, Victor Co., Finland) and Software HT-Soft (Perkin-Elmer). All samples were assayed in six wells and repeated.

Reverse transcription polymerase chain reaction. $\mathrm{PC}-3$ and LNCaP cells $\left(5 \times 10^{5}\right)$ were seeded onto 6-well plates. Total RNA was extracted $48 \mathrm{~h}$ after transfection using TRIzol reagent. Reverse transcription was performed using one step RT-PCR kit. The primers of Egr-1 were 5'-AACAGTGGCA ACACCTTGTG-3' (forward primer) and 5'-ACTGGTAGCT GGTATTGAGG-3' (reverse primer). The primers of human ß-actin were 5'-TCACCAACTGGGACGACAT-3' (forward primer) 5'-GAAGTCCAGGGCGACGTAG-3' (reverse primer). Thermal cycle conditions were as follows: $42^{\circ} \mathrm{C}$ for $30 \mathrm{~min}, 94^{\circ} \mathrm{C}$ for $2 \mathrm{~min}$, followed by 28 cycles of $94^{\circ} \mathrm{C}$ for $15 \mathrm{sec}, 55^{\circ} \mathrm{C}$ for $30 \mathrm{sec}, 72^{\circ} \mathrm{C}$ for $1 \mathrm{~min}$, with a final extension at $72^{\circ} \mathrm{C}$ for $10 \mathrm{~min}$. RT-PCR products were visualized by ethidium bromide-stained agarose gels.

Western immunoblot analysis. PC-3 and LNCaP prostate carcinoma cells lines $\left(5 \times 10^{5}\right)$ were seeded onto 6-well plates. Forty-eight hours after transfection, cells were collected and washed twice by cold PBS, and each well was treated with $50 \mathrm{ml}$ lysis buffer $(2 \mathrm{mmol} / \mathrm{l}$ Tris- $\mathrm{HCl}, \mathrm{pH} \mathrm{7.4,50} \mathrm{mmol/1}$ $\mathrm{NaCl}, 25 \mathrm{mmol} / \mathrm{l}$ EDTA, $50 \mathrm{mmol} / \mathrm{l} \mathrm{NaF}, 1.5 \mathrm{mmol} / \mathrm{l} \mathrm{Na}_{3} \mathrm{VO}_{4}$, $1 \%$ Triton $\mathrm{X}-100,0.1 \%$ SDS, supplemented with protease inhibitors $1 \mathrm{mmol} / \mathrm{l}$ phenylmethylsulfonylfluoride, $10 \mathrm{mg} / \mathrm{l}$ pepstatin, $10 \mathrm{mg} / \mathrm{l}$ aprotinin and $5 \mathrm{mg} / \mathrm{l}$ leupeptin) (all from Sigma). Protein concentrations were determined using the Bradford protein assay. Equal amounts of protein $(40 \mathrm{mg})$ were separated on a $15 \%$ SDS polyacrylamide gel and transferred to a nitrocellulose membrane (Hybond C, Amersham, Freiburg, Germany). Membranes were blocked in 5\% non-fat dry milk in TBS for $1 \mathrm{~h}$ at room temperature and probed with rabbit anti-Egr-1 antibodies (dilution, 1:500 Santa Cruz Biotechnology, USA) overnight at $4^{\circ} \mathrm{C}$. After 3 times washing with TBS containing $0.1 \%$ Tween-20, membranes were incubated with anti-rabbit $\mathrm{IgG}$-horseradish-peroxidase (1:5000, Santa Cruz Biotechnology), and developed by luminol mediated chemiluminescence (Appylgen Technologies, Inc., China). To confirm equal protein loading, membranes were reprobed with a 1:1000 dilution of an anti-actin antibody (Santa Cruz Biotechnology). Densitometric analyses were performed using Scion Image software (25).

Flow cytometry. PC-3 and LNCaP prostate carcinoma $\left(5 \times 10^{5}\right)$ cell lines were seeded in triplicate onto 6-well plates, and cultured in RPMI-1640 supplemented with 100 ml/l FBS. When transfected for $48 \mathrm{~h}$, the cells were collected and washed with ice-cold PBS, and fixed in $70 \%$ ethanol overnight at $4^{\circ} \mathrm{C}$. The fixed cells were pelleted, washed in PBS, resuspended in PBS containing $0.1 \mathrm{mg} / \mathrm{ml}$ of propidium iodide, and analysed by flow cytometry.

Soft agar colony formation assay. The effect of Egr-1 siRNA on colony formation ability of the PC-3 cells was assessed by soft agar colony formation assay. The assay was done in 6well plates; in each well, $2 \mathrm{ml}$ of $0.5 \%$ agar (in culture medium) was layered in the bottom followed by $1 \mathrm{ml}$ of $0.38 \%$ agar as the top layer. Approximately 2000 cells were 


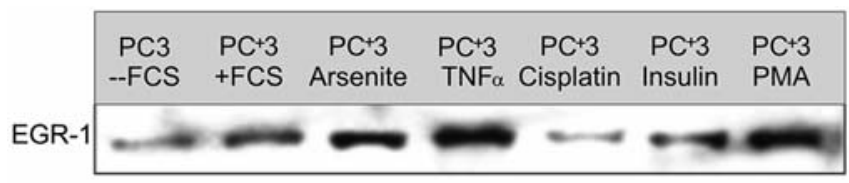

egr-1

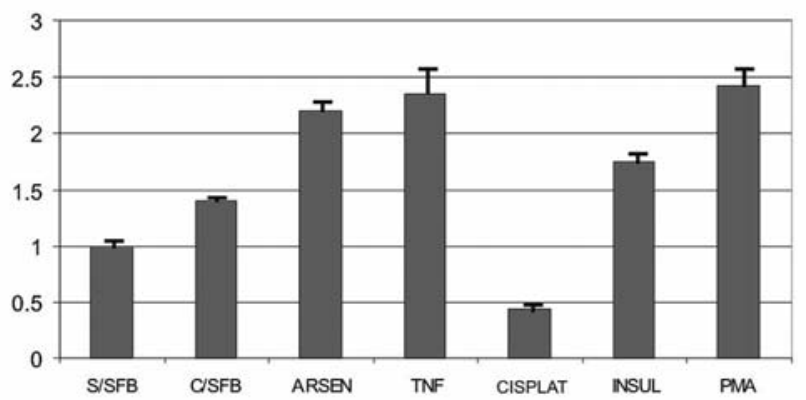

Figure 1. Expression of Egr-1 in prostate carcinoma PC-3 treated with various stimuli. To determine the expression of Egr-1 in prostate cell lines, the PC-3 cells were treated without and with FCS, arsenite, TNF- $\alpha$, cisplatin, insulin and PMA. Egr-1 was examined one hour after treatment by Western blot assay. Arsenite, TNF $\alpha$ and PMA strongly induced Egr-1 activation, compared to the cells treated with cisplatin, insulin and FCS (10\%). The induction without FCS was only marginal.

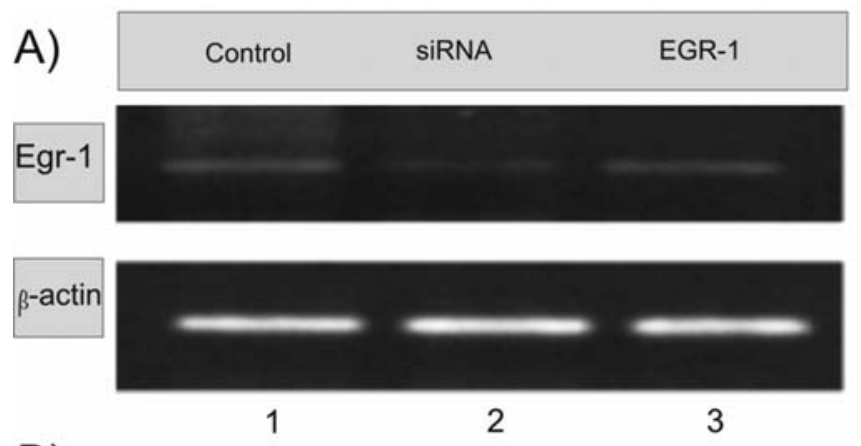

B)

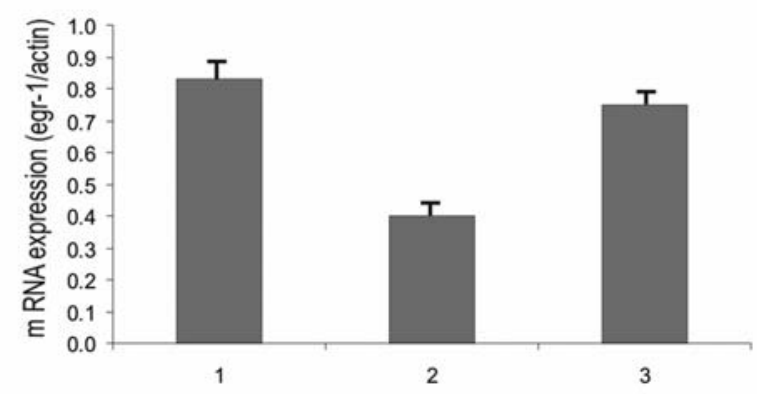

Figure 2. Expression of Egr-1 mRNA in different groups of PC-3 cells. (A) Egr-1 mRNA expression in RT-PCR assay; (B) Egr-1 mRNA expression in PC-3. 1, untreated; 2, treated with Egr-1 siRNA; 3, treated with non-silencing siRNA. Data are expressed as mean \pm SD of three experiments, Egr-1 siRNA group vs. non-silencing siRNA group, $\mathrm{P}<0.01$; Egr-1 siRNA group vs. untreated group, $\mathrm{P}<0.01$.

then plated over the top layer. The cells were treated with Egr-1 siRNA and maintained at $37^{\circ} \mathrm{C}$ in a humidified $5 \%$ $\mathrm{CO}_{2}$ atmosphere. At day 14 post-treatment, plates were

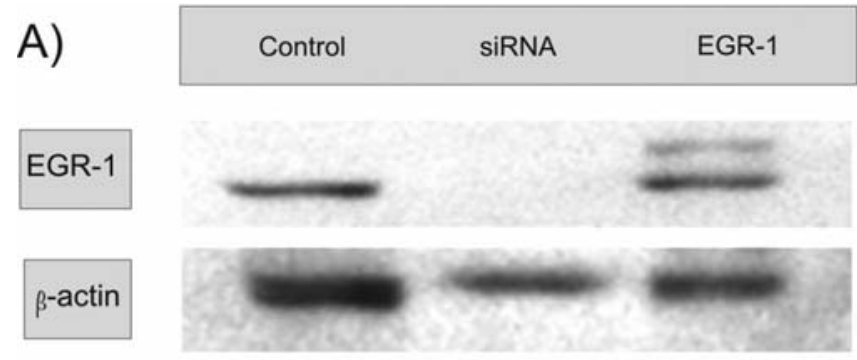

B)

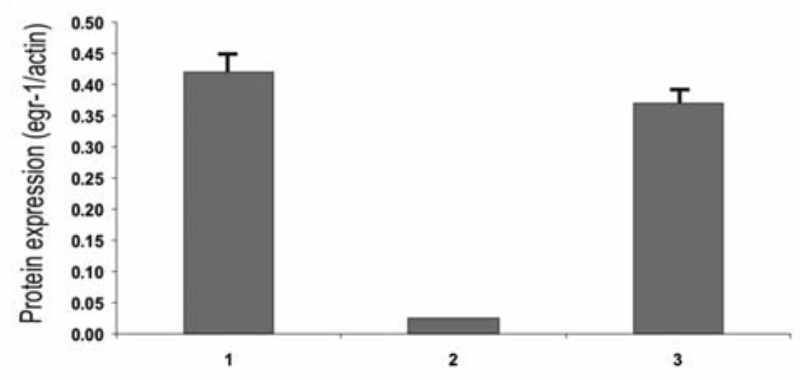

Figure 3. Effect of siRNA against Egr-1 in the expression of EGR-1 protein. Western blot assay of EGR-1 protein expression in PC-3 cells. (A) EGR-1 protein expression in Western blot assay; (B) EGR-1 protein expression in PC-3. 1, untreated; 2, treated with Egr-1 siRNA; 3, treated with pCMV expression vector. Data are expressed as mean $\pm \mathrm{SD}$ of three experiments, Egr-1 siRNA group vs. expressing Egr-1 group, $\mathrm{P}<0.01$; Egr-1 siRNA group vs. untreated group, $\mathrm{P}<0.01$.

assessed for size and number of colonies (original magnification, x4). Colonies (in a representative field) are indicated.

\section{Results}

EGR-1 activity in prostate carcinoma cell lines $P C-3$ treated with various stimuli (Fig. 1). EGR-1 is among the early response nuclear factors that play an important role in the regulation of several genes. To determine the activity of Egr-1 in PC-3 cells, we treated the cells with various stimuli. FCS $10 \%$, arsenite, TNF- $\alpha$ and PMA strongly activates Egr-1 expression. In contrast, insulin, cisplatin and FCS $0.5 \%$ induces a marginal activation of Egr-1 activity.

Effect of siRNA against the expression of Egr-1 gene in PC-3 prostate carcinoma cell line. To examine the specific effect of Egr-1 siRNA treatment on EGR-1 expression in PC-3 prostate carcinoma cell lines, the Egr-1 mRNA and protein expression levels were determined quantitatively with RTPCR and Western blot analyses, respectively. Results are displayed in Figs. 2 and 3.

Egr-1 mRNA (Fig. 2) and protein (Fig. 3) were strongly expressed in prostate carcinoma cells lines as reflected by RT-PCR (Fig. 2) and Western blot (Fig. 3). The inhibition rate of Egr-1 mRNA after transfection with specific Egr-1 siRNA was $44.52 \%$. The inhibition rate of EGR-1 protein after transfection with specific Egr-1 siRNA was $40.17 \%$. Egr-1 expression was decreased significantly at $48 \mathrm{~h}$ after transfection with specific Egr-1 siRNA.

Effect of Egr-1 siRNA on cell proliferation of PC-3 and LNCaP prostate carcinoma cell lines (Fig. 4). To determine 


\section{A. PC-3 cells}

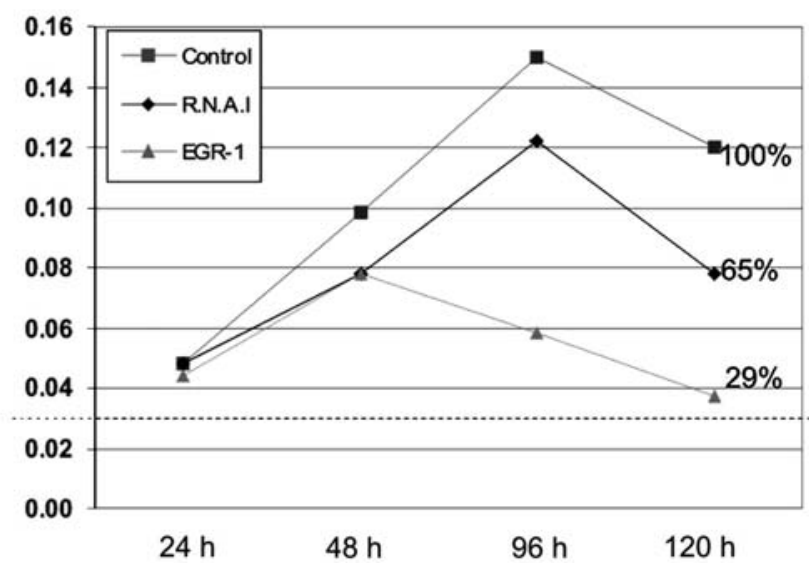

\section{B. LNCaP cells}

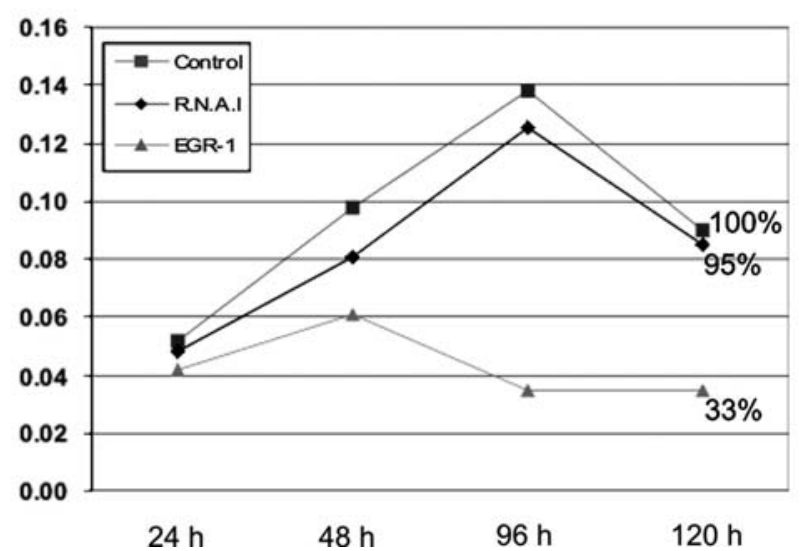

Figure 4. Cell viability: PC-3 and LNCaP prostate carcinoma cell lines were cultured and transfected with Egr-1 siRNA and pCMV-Egr-1. Cells transfected with the empty vector was used as control. One of two similar experiments is shown.

whether inhibition of EGR-1 affects cell proliferation in PC-3 and LNCaP cells , metabolic activity at 24, 48, 96 and $120 \mathrm{~h}$ was determined by the MTT assay. The cell viability was reduced significantly after treatment with specific survivin siRNA $(\mathrm{P}<0.01)$ at $24,48,96$ and $120 \mathrm{~h}$ as compared with non-silencing siRNA treatment or untreated controls.

Effect of Egr1-siRNA on cell cycle distribution and apoptosis (Fig. 5). Next, we compared the cell cycle profile of control PC-3 cells, Egr-1 expressing PC-3 cells and Egr-1 siRNA treated PC-3 cells. The DNA profiles showed that only $11 \%$ of control cells were in $\mathrm{S}$ phase compared with $9 \%$ in cells treated with Egr-1 siRNA and with $7 \%$ in Egr-1 expressing cells, and $34 \%$ of control cells were in $\mathrm{G}_{1}$ phase vs. $20 \%$ in Egr-1 siRNA cells and with $29 \%$ in Egr-1 expressing cells.

Effect of Egr-1 siRNA on cell tumorigenicity (Fig. 6). To address whether Egr-1 expression maintains the PC-3 tumorigenic phenotype, we performed soft agar assay. PC-3 transfected with the empty vector and PC-3/Egr-1 siRNA expressing cells were plated in soft agar. As expected control
A.

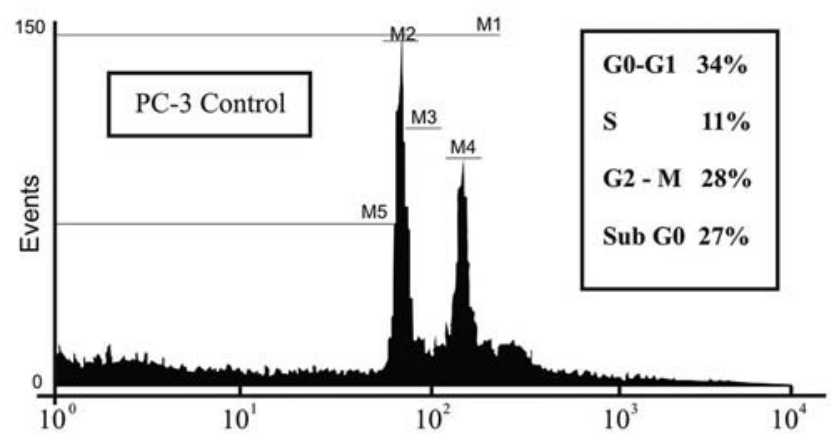

B.

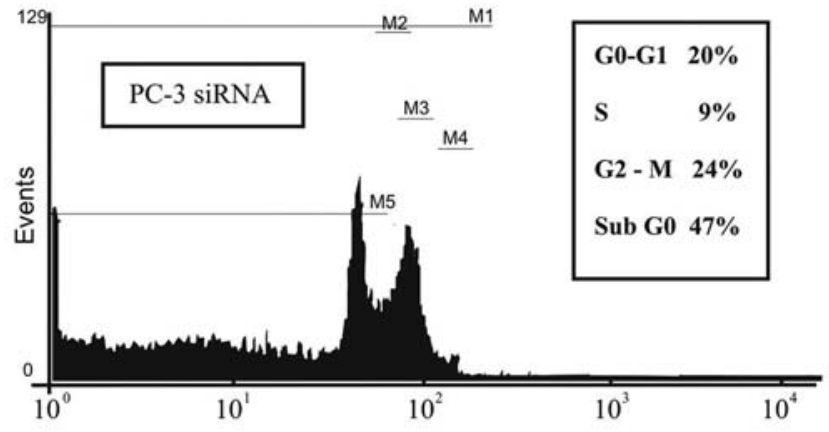

C.

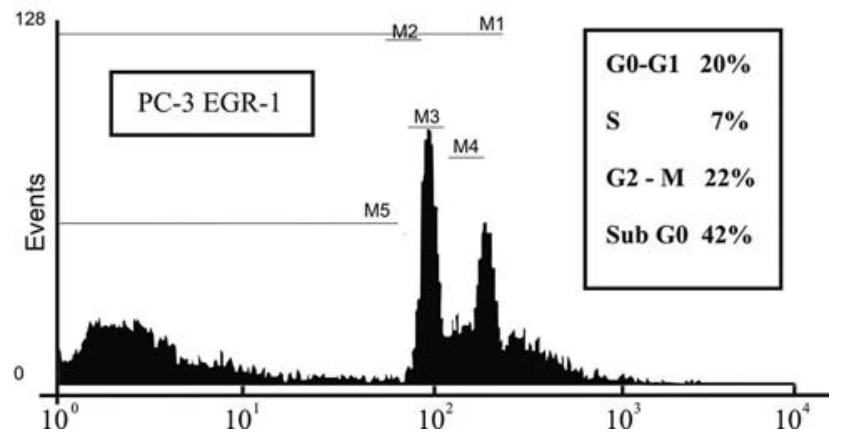

Figure 5. DNA content analysis in PC-3 carcinoma cell lines. After $120 \mathrm{~h}$ of treatment, the cells were fixed, stained using propidium iodide, an analyzed. PC-3 control untransfected cells. PC-3 cells transfected with the Egr-1 siRNA and PC-3 cells transfected with pCMV-Egr-1 expression vector. One of two similar experiments is shown.

cells grew without problem in soft agar. By contrast, Egr-1 siRNA treated cells were able to decrease the ability of these cells to form colonies in soft agar. Together, these data demonstrate that Egr-1 siRNA can induce PC-3 growth arrest and loss of tumorigenic potential.

\section{Discussion}

It has been demonstrated that the inhibition of apoptosis promotes mitotic progression in cancer cells $(26,27)$. Based on its specific overexpression in a vast majority of solid cancers and its anti-apoptotic function, Egr-1 represents a suitable target for antitumor approaches. The inhibition of Egr-1 blocks the anti-apoptosis and mitotic progression in 


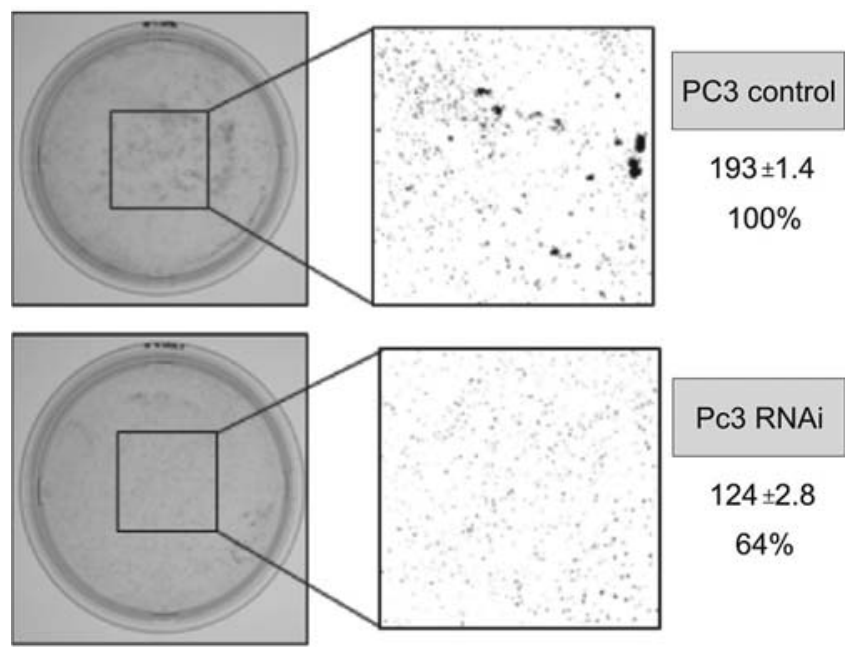

Figure 6. Colony-formation assays in soft agar. Cells (10000) were seeded onto plates, and after 14 days of treatment the cells were stained using crystal violet. Analysis of the appearance of the foci was performed after 2 weeks. One of two similar experiments is shown.

tumor cells $(2,3,28,29)$, as a result, tumor development is suppressed. In this way, Egr-1 has attracted considerable attention as a possible target for prostate cancer treatment. Degradation of mRNA mediated by siRNA is a powerful means of specifically knocking down the expression of a target gene $(20,21)$. RNAi is an evolutionarily conserved phenomenon in which gene expression is suppressed by the introduction of homologous double-stranded RNAs (dsRNAs). Synthetic siRNA can trigger an RNA interference response in mammalian cells and induce strong inhibition of specific gene expression $(30,31)$. SiRNA can transiently mediate specific degradation of homologous messenger RNA (mRNA), silencing the expression of the targeted gene $(30,31)$. Since Egr-1 is important for the survival of various human tumors, Egr-1 siRNA could become an effective therapeutic agent for tumors with overexpression of EGR-1. In addition, it is reported that the effect of RNAi may be greatly different, targeting to different sequences of the gene (32-34). It is therefore, very important to find the proper sequence. The sequence designed by us has been confirmed effective in their research.

In the present study, we have demonstrated that a siRNA against the mRNA of Egr-1 blocked the production of the Egr-1 protein through bloking the transduction process of the Egr-1 mRNA. The Egr-1 siRNA blocked Egr-1 transduction, while the non-silencing Egr-1 did not. siRNA against Eg-1 mRNA prevents the expression of EGR-1 through promoting the degradation of the Egr-1 mRNA. This event could lead to consequent activation of Egr-l target genes, such as PTEN, TGF-B1, p53 and fibronectin, which serve to maintain normal growth regulation (35-39).

We found that the protein level of EGR-1 was decreased by the expression of siRNA against the Egr-1 transcription product, which resulted in the suppression of the EGR-1 mRNA proteins and consequently a decreased activity of EGR-1 in the cells. Since Egr-1 expression is severely impaired in prostate cancer cells $(9,28,40)$, this loss of EGR-1 protein is probably a critical factor in the survival of these cells.
Our results demonstrate that the RNA interference could efficiently suppress the Egr-1 expression in PC-3 and LNCaP cells. At $48 \mathrm{~h}$ after transfection, the expression inhibition rate was $44.52 \%$ at mRNA level detected by RT-PCR and $40.17 \%$ at protein level by Western blot analysis. Similarly, the cell proliferation was also affected. The apoptosis rate was $3.56 \%$ and the number of cells was decreased in $\mathrm{G}_{0} / \mathrm{G}_{1}$ phase from 34 to $20.6 \%$, and decreased in $S$ and $G_{2} / M$ phase at $48 \mathrm{~h}$ after transfection. The DNA profiles showed that only $11 \%$ of control cells were in S phase compared with $9 \%$ in cells treated with Egr-1 siRNA and with $7 \%$ in Egr-1 expressing cells, and $34 \%$ of control cells were in $\mathrm{G}_{1}$ phase vs. $20 \%$ in Egr-1 siRNA cells and with 29\% in Egr-1 expressing cells. In addition, luciferase assay in these cells demonstrated that the transcription activity was not afected, suggesting a post-trancriptional effect of siRNA in these cell lines (data not shown). It have been reported that the effect of siRNA may be greatly different, targeting to different sequence of the gene (41-44). It is therefore, very important to find the proper sequence. So in our study, we synthesized this siRNA duplex with a thymidine overhang on $3^{\prime}$ terminus in vitro to diminish the Egr-1 expression of prostate carcinoma PC-3 and $\mathrm{LNCaP}$ cell lines and to impair its growth potential.

We observed that PC-3 and LNCaP cells transfected with Egr-1 siRNA grew slowly as compared with the control groups. Egr-1 siRNA showed anti-proliferation function. RTPCR and Western blot findings demonstrated that Egr-1 mRNA and protein expression were reduced by over $40 \%$, and Egr-1 gene was blocked in PC-3 and LNCaP cells transfected with Egr-1 siRNA at the level of transcription and protein expression. Flow cytometry revealed that the cell growth inhibition by Egr-1 siRNA was a result of cell cycle arrest at $G_{0} / G_{1}$-phase and induction of apoptosis indicated by annexin $\mathrm{V}$ (early apoptosis) and propidium iodide assay (late apoptosis). The possible mechanism is that Egr-1 is characterized by cell cycle-dependent expression, i.e., it is expressed in $\mathrm{G}_{2} / \mathrm{M}$.

In our study, after PC-3 and LNCaP cells were transfected with Egr-1 siRNA, the number of cells in $\mathrm{G}_{0} / \mathrm{G}_{1}$ was remarkably increased, and the number of cells in $S$ or $G_{2} / M$ decreased. The effect showed the same mechanism.

The above-mentioned findings confirm that chemically synthesized siRNAs can specifically block Egr-1 gene expression, inducing cell apoptosis and inhibiting the growth of prostate carcinoma cell lines.

In conclusion, our data suggest that Egr-1 gene can be regarded as a very good target gene in genetic therapy for prostate carcinomas and the use of Egr-1 siRNA deserves further investigations as a novel approach to cancer therapy.

\section{Acknowledgements}

We would thank Dr Anna Bigas Salvans (Laboratory of Transcriptional control of cell differentiation. Institut Recerca Oncologica, Barcelona, Spain) for providing us the pTER vector for expressing the Egr-1 siRNA. We would also thank Dr Dan Mercola (The Sidney Kimmel Cancer Center, La Jolla, San Diego, CA) for providing us the cell lines PC-3 and LNCaP. This study was supported by the Chilean 
National Science Foundation FONDECYT regular grant award 1060774.

\section{References}

1. Eichelberger L, O Koch M, Eble J, Ulbright T, Juliar B and Cheng L: Maximum tumor diameter is an independent predictor of prostate-specific antigen recurrence in prostate cancer modern pathology. Oncol Rep 18: 886-890, 2005.

2. Virolle T, Krones-Herzig A, Baron V, Gregorio GG, Adamson ED and Mercola D: Egr1 promotes growth and survival of prostate cancer cells: identification of novel Egr1 target genes. J Biol Chem 278: 11802-11810, 2003.

3. Eid MA, Kumar MV, Iczkowski KA, Bostwick DG and Tindall DJ: Expression of early growth response genes in human prostate cancer. Cancer Res 58: 2461-2472, 1998.

4. Scharnhorst V, Menke AL and Attema J: EGR-1 enhances tumor growth and modulates the effect of the Wilms' tumor 1 gene products on tumorigenicity. Oncogene 19: 791-800, 2000 .

5. Pignatelli M, Luna-Medina R, Perez-Rendon A, Santos A and Perez-Castillo A: The transcription factor early growth response factor-1 (EGR-1) promotes apoptosis of neuroblastoma cells Biochem J 373: 739-746, 2003.

6. Houston P, Campbell CJ, Svaren J, Milbrandt J and Braddock M: The transcriptional corepressor NAB2 blocks Egr-1-mediated growth factor activation and agiogenesis. Biochem Biophys Res Commun 283: 480-486, 2001

7. Collins S, Lutz MA, Zank PA, Anders R, Kersh G and Powell JD: Opposing regulation of $\mathrm{T}$ cell function by Egr-1/NAB2 and Egr-2/Egr-3. Eur J Immunol 38: 528-536, 2008.

8. Amorino G, Hamilton V, Valerie K, Dent P, Lammering G and Schmidt-Ullrich R: Epidermal growth factor receptor dependence of radiation-induced transcription factor activation in human breast carcinoma cells. Mol Biol Cell 13: 2233-2244, 2002.

9. Adamson ED and Mercola D: Egr1 transcription factor, multiple roles in prostate tumor cell growth and survival. Tumor Biol 23 93-102, 2002.

10. Banks MF, Gerasimovskaya EV, Tucker D, Frid MG, Carpenter TC and Stenmark KR: Egr-1 antisense oligonucleotide inhibit hypoxia-induced proliferation of pulmonary artery adventitial fibroblast. J Appl Physiol 98: 732-738, 2004.

11. Huang RP, Fan Y, De Belle I, Niemeyer C, Gottardis MM, Mercola D and Adamson ED: Decreased Egr-1 expression in human, mouse and rat mammary cells and tissues correlates with tumor formation. Int J Cancer 72: 102-109, 1997.

12. Tuschl T and Borkhardt A: Small interfering RNAs a revolutionary tool for the analysis of gene function and gene therapy. Mol Interv 2: 158-167, 2002.

13. Konnikova L, Kotecki M, Kruger MM, Cochran BH and Miao GY: Downregulation of survivin gene expression by RNA knockdown of STAT3 expression by RNAi induces apoptosis in astrocytoma cells. BMC 3: 23, 2003.

14. Sioud M, Furset G, and Cekaite L: Suppression of immunostimulatory siRNA-driven innate immune activation by 2 modified RNAs. Biochem Biophys Res Commun 361: 122126, 2007.

15. Mikio A, Takayuki I, Masaharu K and Toru K: RNA interference in immune cells by use of osmotic delivery of SiRNA. Biochem Biophys Res Commun 360: 326-333, 2006.

16. Sioud M: Does the understanding of immune activation by RNA predict the design of safe siRNA. Front Biosci 13: 4379-4392, 2008.

17. Hannon GJ and Rossi JJ: Unlocking the potential of the human genome with RNA interference. Nature 431: 371-378, 2004

18. Stevenson M: Therapeutic potential of RNA interference. N Engl J Med 351: 1772-1777, 2004.

19. Devroe E and Silver PA: Retrovirus-delivered siRNA. BMC Biotechnology 2: 15-20, 2002.

20. Persengiev SP, Zhu X and Green MR: Non-specific, concentration-dependent stimulation and repression of mammalian gene expression by small interfering RNAs (siRNA). RNA 10: 12-18, 2004.

21. Sui G, Soohoo C, Affar E, Gay F, Shi Y, Forrester WC and Shi Y: A DNA vector based RNAi technology to suppress gene expression in mammalian cells. Proc Natl Acad Sci USA 99: 55155520,2002 .
22. Jackson AL and Linsley PS: The silence: off-target effects of siRNAs? Trends in genetics. Nat Genet 20: 521-524, 2004.

23. Kawasaki H, Taira K and Morris K: siRNA induced transcriptional gene silencing in mammalian cells. Cell Cycle 4: 442-449, 2005.

24. Inostroza J, Saenz L, Calaf G, Cabello G and Parra E: Role of the phosphatase PP4 in the activation of JNK-1 in prostate carcinoma cell lines PC- 3 and LNCaP resulting in increased AP-1 and EGR-1 activity. Biol Res 38: 163-178, 2005.

25. Liu C, Rangnekar VM, Adamson E and Mercola D: Suppression of growth and transformation and induction of apoptosis by EGR-1. Cancer Gene Ther 5: 3-28, 1998.

26. Kawasaki H, Altieri DC, Lu CD, Toyoda M, Tenjo T and Tanigawa N: Inhibition of apoptosis by survivin predicts shorter survival rates colorectal cancer. Cancer Res 58: 5071-5074, 1998.

27. Thiel G and Cibelli G: Regulation of life and death by the zinc finger transcription factor Egr-1. J Cell Physiol 193: 287-292, 2002.

28. Huang RP, Fan Y and Peng A: Suppression of human fibrosarcoma cell growth by transcription factor, Egr-1, involves down-regulation of Bcl-2. Int J Cancer 77: 880-886, 1998.

29. Uchida H, Tanaka T, Sasaki K, Kato K, Dehari H, Ito Y, Kobune M, Miyagishi M, Taira K, Tahara $\mathrm{H}$ and Hamada $\mathrm{H}$ : Adenovirus-mediated transfer of siRNA against survivin induced apoptosis and attenuated tumor cell growth in vitro and in vivo. Mol Ther 10: 162-171, 2004

30. Shuangli N, Fuessel S, Kotzsch M, Kraemer K, Kappler M, Schmidt U, Taubert H, Wirth M and Meye A: siRNA-mediated down-regulation of survivin inhibits bladder cancer cell growth. Int J Oncol 25: 1065-1071, 2004.

31. Yong $\mathrm{C}$ and Rami M: siRNA pool targeting different sites of human hepatitis B surface antigen efficiently inhibits HBV infection. J Drug Target 16: 140-148, 2008.

32. Kim D and Rossi JJ: Coupling of RNAi-mediated target downregulation with gene replacement. Antisense Nucleic Acid Drug Dev 13: 151-155, 2003.

33. Kaufmann K and Thiel G: Epidermal growth factor and plateletderived growth factor induce expression of Egr-1, a zinc finger transcription factor, in human malignant glioma cells. J Neurol Sci 189: 83-91, 2001

34. Reynolds A, Leake D and Boese Q: Rational siRNA design for RNA interference. Nat Biotechnol 22: 326-330, 2004.

35. Baron V, Vo C and Mercola D: A combination study of Egr-1 antisense with chemotherapeutic drugs in human prostate cancer cells. Oncogene 22: 4194-4204, 2003.

36. Baron V, Adamson ED, Calogero A, Ragona G and Mercola D: The transcription factor Egr1 is a direct regulator of multiple tumor suppressors including TGF beta 1, PTEN, p53, and fibronectin. Cancer Gene Ther 13: 115-124, 2006.

37. Virolle T, Adamson ED, Baron V, Birle D, Mercola D, Mustelin T and De Belle I: The Egr-1 transcription factor directly activates PTEN during irradiation-induced signalling. Nat Cell Biol 3: 1124-1128, 2001.

38. De Belle I, Huang RP, Fan Y, Liu C, Mercola D and Adamson ED: p53 and Egr-1 additively suppress transformed growth in HT1080 cells but Egr-1 counteracts p53-dependent apoptosis. Oncogene 18: 3633-3642, 1999.

39. Svaren J, Ehrig T, Abdulkadir SA, Ehrengruber MU, Watson MA and Milbrandt J: EGR1 target genes in prostate carcinoma cells identified by microarray analysis. J Biol Chem 275: 38524-38531, 2000.

40. Liu C, Yao J, Mercola D and Adamson E: The transcription factor EGR-1 directly transactivates the fibronectin gene and enhances attachment of human glioblastoma cell line U251. J Biol Chem 275: 20315-20323, 2000.

41. Zhao-Ling Q, Ping Z, Ming-Mei C and Zhong-Tian Q: siRNAs targeting terminal sequences of the SARS-associated coronavirus membrane gene inhibit $M$ protein expression through degradation of M mRNA. J Virol Methods 145: 146-154, 2007.

42. Fire A, Xu S, Montgomery MK, Kostas SA, Driver SE and Mello CC: Potent and specific genetic interference by doublestranded RNA in C. elegans. Nature 391: 806-811, 1998.

43. Plasterk RH: RNA silencing: the genome's immune system. Science 296: 1263-1265, 2002.

44. Tijsterman M and Plasterk RH: Dicers at RISC; the mechanism of RNAi. Cell 117: 1-3, 2004. 